ARTICLE

https://doi.org/10.1057/s41599-019-0366-y

\title{
Statistical reliability analysis for a most dangerous occupation: Roman emperor
}

Joseph Homer Saleh ${ }^{1 \star}$

\begin{abstract}
Popular culture associates the lives of Roman emperors with luxury, cruelty, and debauchery, sometimes rightfully so. One missing attribute in this list is, surprisingly, that this mighty office was most dangerous for its holder. Of the 69 rulers of the unified Roman Empire, from Augustus (d. 14 CE) to Theodosius (d. 395 CE), 62\% suffered violent death. This has been known for a while, if not quantitatively at least qualitatively. What is not known, however, and has never been examined is the time-to-violent-death of Roman emperors. This work adopts the statistical tools of survival data analysis to an unlikely population, Roman emperors, and it examines a particular event in their rule, not unlike the focus of reliability engineering, but instead of their time-to-failure, their time-to-violent-death. We investigate the temporal signature of this seemingly haphazardous stochastic process that is the violent death of a Roman emperor, and we examine whether there is some structure underlying the randomness in this process or not. Nonparametric and parametric results show that: (i) emperors faced a significantly high risk of violent death in the first year of their rule, which is reminiscent of infant mortality in reliability engineering; (ii) their risk of violent death further increased after 12 years, which is reminiscent of wear-out period in reliability engineering; (iii) their failure rate displayed a bathtub-like curve, similar to that of a host of mechanical engineering items and electronic components. Results also showed that the stochastic process underlying the violent deaths of emperors is remarkably well captured by a (mixture) Weibull distribution. We discuss the interpretation and possible reasons for this uncanny result, and we propose a number of fruitful venues for future work to help better understand the deeper etiology of the spectacle of regicide of Roman emperors.
\end{abstract}

\footnotetext{
${ }^{1}$ Georgia Institute of Technology, Atlanta, USA. *email: jsaleh@gatech.edu
} 


\section{Introduction}

W hat did a Roman emperor have in common with a gladiator? The latter had better odds of surviving a fight than the former had of avoiding a violent death. Popular culture traditionally associates the lives of Roman emperors with luxury, cruelty, and debauchery, sometimes rightfully so. One missing attribute in this list is, surprisingly, that this mighty office was most dangerous for its holder, as the statistics will show. Consider the following: of the 69 rulers of the unified Roman Empire, from Augustus (d.14 CE) to Theodosius (d. $395 \mathrm{CE}), 43$ emperors suffered violent death, that is $62 \%$, either by assassination, the most common mode of death, suicide, or during combat with a foreign enemy of Rome ${ }^{1}$ (Fig. 1). To put this statistic in context and better appreciate its magnitude, compare it with what is considered nowadays a seriously dangerous activity: Himalaya mountaineering. Climbers that summit above $8000 \mathrm{~m}$ in the Himalayas have a risk of death of about 4\%, a relatively consistent figure for the past 50 years (Amalberti et al., 2005). Roman emperors had an order of magnitude greater risk of violent death than these intrepid climbers.

The odds of survival for a Roman emperor were roughly equivalent to playing the Russian roulette with a six-chambered revolver, in which the participant places not one but four bullets, spins the cylinder to randomize the outcome, and pulls the trigger with the muzzle against his head.

This sinister comparison conjures the notion of random variable, a central protagonist in our story. That the likelihood of violent death for an emperor was high was well-known, if not quantitatively at least qualitatively as far back as Edward Gibbon's publication of the first volume of his Decline and Fall of the Roman Empire (1776). In discussing the highly energetic emperor Aurelian (ruled from 270 to $275 \mathrm{CE}$ ), nicknamed restitutor orbis, restorer of the world or the unity of the Roman empire in the troubled third century (Watson, 1999), one can almost feel Gibbon's disappointment when reflecting on the emperor's murder ${ }^{2}$ :

Such was the unhappy condition of the Roman emperors, that, whatever might be their conduct, their fate was commonly the same. A life of pleasure or virtue, of severity or mildness, of indolence or glory, alike led to an untimely grave; and almost every reign is closed by the same disgusting repetition of treason and murder [emphasis added].

He then added, "the Roman senators heard, without surprise, that another emperor had been assassinated in his camp".

It is worth taking a little historical detour at this point, back to the time before this track record of treason and murder Gibbon refers to was even started, to revisit a popular landmark quotation and understand it in a new light, Julius Caesar's "Iacta alea est"...

Of dice and men. And Roman emperors. As Caesar contemplated his decision to cross the shallow Rubicon river with his legion, a capital offense for himself and his soldiers, he is said to

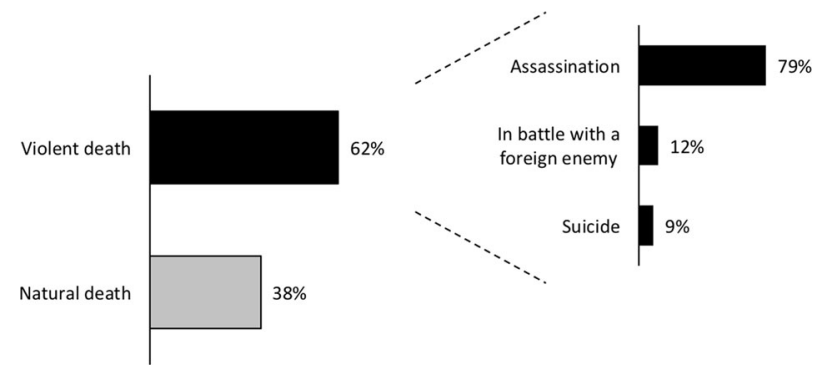

Fig. 1 Deaths and failure modes of the rulers of the unified Roman Empire. have exclaimed, according to Suetonius, "iacta alea est" (Suetonius, 1998). The expression is commonly translated as "the die is cast", or more resolutely, "let the die be cast", and it is taken to signify the passing of the point of no return in an irrevocable course of action. For anyone familiar with the game of dice, which Roman soldiers and several emperors were fond of, the emphasis of the exclamation is less on the passing of the point of no return, and more on the aleatory nature of the possible outcome. What is the likelihood that the outcome will be, say, odd? Or a particular number given a four-sided or six-sided dice? What outcomes did Caesar contemplate? There is obviously the fate of his undertaking: will the Roman Republic endure, or is this the last nail in its coffin? What will his own fate be? Will he be successful, or will he meet a violent death? In crossing the Rubicon, Caesar significantly narrowed down the scope of possible outcomes he could face.

Beyond this original throw of dice, Caesar provided a metaphor, not just for himself, but for every subsequent emperor: upon confirmation by the senate, or being chosen by the legions or the praetorian guards, every emperor could have exclaimed, "iacta alea est" and was in effect throwing a dice for his life. In retrospect, we now know that collectively the rulers of the unified Roman Empire had a $62 \%$ chance of dying a violent death. This is roughly the equivalent of associating four outcomes, for example $\{1,2,3,4\}$ with this gruesome end, and rolling a six-sided fair dice. Only those who rolled a 5 or 6 got to die of a natural death. This is a seemingly more benign but equally potent metaphor than the previous Russian roulette.

What is not known, however, and has never been examined to date is another random variable associated with these rulers, their time-to-failure or time-to-violent-death. A brief discussion of reliability engineering is in order to better understand this idea and the focus of this work.

\section{Reliability engineering and Roman emperors: from time-to- failure to time-to-violent-death}

Reliability is a popular concept that has been celebrated for years as a commendable attribute of a person or an equipment. Although many words in the English language have been coined by or attributed to Shakespeare, it seems that we owe the word reliability to another English author, the poet Samuel Coleridge (1772-1834). In praising a friend, Coleridge wrote (Coleridge, 1983; Saleh and Marais, 2006):

He inflicts none of those small pains and discomforts which irregular men scatter about them and which in the aggregate so often become formidable obstacles both to happiness and utility; while on the contrary he bestows all the pleasures, and inspires all that ease of mind on those around him or connected with him, with perfect consistency, and (if such a word might be framed) absolute reliability.

Since then, reliability engineering has developed into an important discipline that pervades many aspects of our modern, technologically intensive world (Hoyland and Rausand, 2009). The foundational idea in reliability engineering is that the timeto-failure, $T_{\mathrm{f}}$, of an item is stochastic in nature, it is a random variable. Roughly speaking, reliability, $S(t)$, is defined as the probability that an item is still operational at time $t$; it has not failed and is till performing its function up to this time:

$$
S(t) \equiv \operatorname{Pr}\left(T_{\mathrm{f}}>t\right)
$$

$S(t)$ is also known as the survival or survivor function. Reliability engineering is then concerned with quantifying this probability 
over the life of an item. This is sufficient for our purposes. Another useful concept in reliability engineering is that of failure rate. It is less important for our story but is worth mentioning. While reliability is the complement of the cumulative distribution function $(\mathrm{CDF})$ of the random variable time-to-failure $\left(T_{\mathrm{f}}\right)$, the failure rate $\lambda(t)$ is its conditional probability density function defined as

$$
\lambda(t) \equiv \frac{\operatorname{Pr}\left(t<T_{\mathrm{f}} \leq t+\mathrm{d} t \mid T_{\mathrm{f}}>t\right)}{\mathrm{d} t}=-\frac{1}{S(t)} \frac{\mathrm{d} S(t)}{\mathrm{d} t}
$$

In words, it is the likelihood per unit time that a failure will occur between $t$ and $t+\mathrm{d} t$ given that it has not yet occurred by the time $t$.

What does this have to do with Roman emperors? It is not that they were unlike Coleridge's friend, it is that we can treat their time-to-violent death as a random variable, and examine it with the same tools of reliability engineering, or more broadly with the statistical tools of life data analysis-the double entendre (life) is not intended but unavoidable here.

Life data analysis, also known as survival analysis, refers to the analysis and probabilistic modeling of the time-to-event as a random variable. The event can be broadly defined, and several academic disciplines have adopted this statistical tool for their particular interests. For example, beyond reliability engineering where the interest is in the time to failure of an item, survival analysis is also broadly used in medical research and public health, where the interest is in, for example, the time to development of a disease, the time to remission after treatment, or the time to death after prognostic. More details can be added to further qualify these events. Survival analysis is also increasingly used in quantitative political science and sociology to examine, for example, the time to break-down of cease fires, the time to landing a first job after graduation, or the time to having one's first child.

The next section extends the application of these statistical tools to an unlikely population, Roman emperors, and it examines a particular event in their rule, not unlike the focus of reliability engineering, but instead of their-time-to-failure, their time-to-violent-death.

\section{Data and methods}

The data for this work was obtained for De Imperatoribus Romanis, a peer-reviewed online encyclopedia of Roman emperors [DIR] (De Imperatoribus Romanis DIR, 2019). The entry for each emperor was written by a leading scholar in the field. The Imperial Index provides the list of the rulers of the united Roman empire, along with the many usurpers who unsuccessfully claimed the mantle. The data is fairly standard and generally accepted, and consequently it was considered beyond the scope of the present work to subject it to further quality control. Only legitimate emperors confirmed by the Roman senate are here considered ${ }^{3}$.

For example, after the troubled period following the murder of both $\operatorname{Commodus}^{4}$ (d. $192 \mathrm{CE}$ ), and Pertinax (d. $\left.193 \mathrm{CE}\right)$, a notorious event in the history of Rome took place: the praetorian guards effectively sold the empire to the highest bidder, Didius Julianus. This shameful event came to be known as the "auction of the empire", and it was neither the first time nor the last that the praetorians acted as emperor-makers (the first such instance was the selection of Claudius following the murder of Gaius Little-Boots or Caligula, as he was nicknamed by the soldiers of his famed father, Germanicus). Even though Didius Julianus was considered a usurper by his successor, Septimius Severus and others, the fact that he was proclaimed by the senate makes him a "legitimate" emperor for our purposes. As a side note, Didius
Julianus is noted for two memorable feats: the manner in which he became emperor, and for holding one of the shortest reigns for an emperor, 66 days, before he was executed.

Another point with the data that should be mentioned is censoring. Censoring in a statistical sense occurs when life data for the analysis of a set of items is "incomplete". This situation occurs frequently in medical research and reliability engineering, and it can happen because some individuals under study are lost to follow-up, or some items are removed prior to the observation of failure or the event of interest. In our case, about $38 \%$ of the individuals are (right-)censored by virtue of having died of illness or old age. But two emperors, Diocletian and Maximianus, are censored through another improbable mechanism: abdication. Diocletian rose through the military ranks to become emperor in $284 \mathrm{CE}$, and he put an end to the imperial crisis that plagued much of the third century, since the murder of the young Alexander Severus (d.235 CE). Diocletian also undertook many reforms, administrative and military, which gave the Roman empire another lease on life for centuries to come, at least in the East. Then, in $305 \mathrm{CE}$ he abdicated and devoted himself to gardening for the rest of his life at his palace in Split on the beautiful Croatian coast $^{5}(d .316 \mathrm{CE})$. For the purpose of this study therefore, Diocletian, and his co-emperor Maximianus, who also abdicated, perhaps unwillingly, contribute censored life data to this analysis. The fact that Maximianus was killed or committed suicide 5 years after he had abdicated does not qualify him to be counted among the emperors who met a violent death since he was no longer one.

The quality and limitation of the sources has to be acknowledged, even for such major events as the death or assassination of an emperor. The sources for the ancient history of interest here are unevenly distributed. They are patchy at times, sometimes contradictory, and often proceed with innuendos and inferences. For example, Suetonius relates several rumors that Caligula, or an attendant, may have poisoned or smothered the emperor Tiberius (d. $37 \mathrm{CE})$ after the latter had fallen ill. The extent of hatred this emperor inspired across all social classes in Rome may have contributed to these rumors. But the likelihood that Tiberius's death was the result of foul play is slim, and the general consensus tilts away from this possibility. However, this lack of certainty in things related to ancient history has to be contended with, especially in the cases of dubious deaths of emperors when competing narratives are available. A similar example occurs with Claudius (d. $54 \mathrm{CE})$, but the general consensus in this case is that he was indeed poisoned by his wife Agrippina to expedite the ascension of her son, Nero. For the purpose of this work, Claudius is therefore considered to have met a violent death, whereas Tiberius is not.

Two more cases are worth noting, both for their strangeness and for the parallel they offer with the deaths of Tiberius and Claudius. Numerianus was acclaimed Augustus in $283 \mathrm{CE}$ upon his father's death. He was married to the daughter of the prefect of the praetorian guard, Flavius Aper. Upon returning from Syria, the young emperor fell ill, and his entourage, including Aper, let it be known that the emperor had an eye inflammation, and therefore had to travel in a closed litter. For several days, no one checked on the emperor until the soldiers waiting on him noticed the smell of decay. They opened the litter only to find the decomposing body of the emperor. An imperial commander accused Aper of this sordid deed and cut him down. The soldiers then proclaimed this commander, Valerius Diocles, emperor, and he would become Diocletian, one of the most capable emperors, militarily and administratively. So what are we to make of this story? Numerianus dies under mysterious circumstances. But was it Aper's ambition to eliminate his son-in-law and assume the mantle in his stead? Was Diocles more cleverly devious and 
eliminated in one stone both the emperor and the Praetorian Prefect to become emperor himself? Or was Numerianus simply unlucky and succumbed to his illness, after which events just unfolded haphazardly? There can only be speculation at this point, and these issues cannot be resolved. For the purpose of this work, Numerianus's death is treated like that of Tiberius not Claudius, that is, it is not considered the result of foul play. A similar situation occurred some 40 years earlier, with the suspicious death of the child emperor Gordian III (d. $244 \mathrm{CE})$. The machinations of his newly appointed Praetorian Prefect Julius Philippus, later the emperor Philip the Arab, are suspected in this deed. These again are speculation, and for the purpose of this work, Gordian III death is treated like that of Tiberius. The statistical results that follow therefore err on the side of caution and are most likely conservative.

Aside from these vexing little problems with the data, the rest of the statistical analysis in this work is straightforward: it starts with the nonparametric Kaplan-Meier estimator for handling censored data, then proceeds with the maximum-likelihood method for estimating the parameters of a particular probability distribution function ${ }^{6}$. Emperors who met a violent death within the first year of their rule are assigned a 0.5-year reign, since the exact number of days is not always accurately known. After the first year of rule, the time is rounded up to the year when death occurred. The data is provided in the appendix in Table A1.

\section{Results and discussion}

In this section, we investigate the temporal signature of this seemingly haphazardous stochastic process that is the violent death of a Roman emperor. We also examine whether there is some structure underlying the randomness of this process or not, and we discuss parallels with results in reliability engineering.

Non-parametric and parametric analyses, and interpretation. The data in Table A1 is treated with the Kaplan-Meier estimator, and the results are provided in Fig. 2. The longest rule was that of Augustus, who established the principate, as the early empire was called. He ruled for 45 years, and since he died peacefully of old age, he contributes censored data to the analysis. The results in Fig. 2 are shown up to this last time-to-violent death.

Figure 2 reads as follows: at the 3-year mark for example, an emperor had $64 \%$ chance of not having met a violent death; at the 7 -year mark, those chances drop to $50 \%$, a mere coin toss. The likelihood of a violent death is the complement of these figures, $36 \%$ and $50 \%$, respectively.

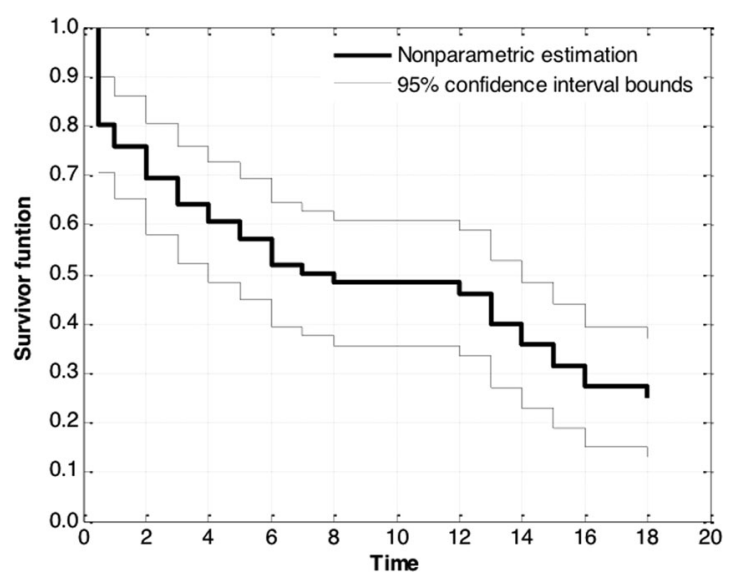

Fig. 2 Survivor (reliability) function of Roman emperors as a function of their time in office.
What does this mean? Three salient features in this figure are important to note:

i. Emperors faced a significantly high risk of violent death in the first year of their rule. This risk remained high but progressively dropped over the next 7 years. This is reminiscent of infant mortality in reliability engineering, a phase during which weak components fail early on after they have been put into service, often because of design or manufacturing defects for example. Roman emperors therefore experienced a form of infant mortality;

ii. The reliability or survivor function stabilizes by the 8th year of rule. The emperors could lower their guard a bit if they made it to 8 years...

iii. ... but not for long: the risk of violent death picks up again after 12 years of rule. This suggests that new mechanisms or processes drove another round of murder. This is reminiscent of wear-out period in reliability engineering, a phase during which the failure rate of components, especially mechanical items, increases because of fatigue, corrosion, or wear-out. Roman emperors therefore also experienced wear-out mortality.

A Weibull plot for the previous nonparametric results is provided in Fig. 3. The plot displays $\ln \{-\ln [S(t)]\}$ as a function of $\ln (t)$. If the data points obtained are aligned, it can be concluded that the data effectively arises from a Weibull distribution, that is, the underlying parametric distribution giving rise to this violentdeath process is indeed a Weibull. The Weibull survivor function is widely used in reliability engineering and survival analysis because it is a highly flexible parametric model, and it is given by

$$
S(t)=\exp \left[-\left(\frac{t}{\theta}\right)^{\beta}\right]
$$

$\beta$ is termed the shape parameter, and $\theta$ the (temporal) scale parameter or characteristic life. A shape parameter $\beta<1$ is indicative of or reflects the prevalence of infant mortality in the items under study, whereas $\beta>1$ indicates the prevalence of wearout failures (decreasing versus increasing failure rates, respectively). Equation (3) is equivalent to a linear Weibull plot (Eq. (4)):

$$
S(t)=\exp \left[-\left(\frac{t}{\theta}\right)^{\beta}\right] \Leftrightarrow \ln \{-\ln [S(t)]\}=\beta \ln (t)-\beta \ln (\theta)
$$

It is interesting that a stochastic process as unconventional and haphazardous as the violent death of a Roman emperor-over a

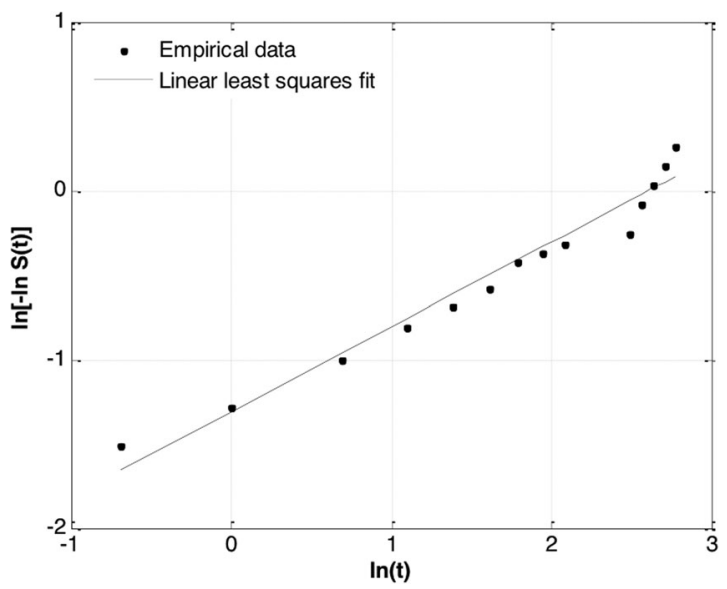

Fig. 3 Weibull plot of the survivor function of Roman emperors, and linear least square fit $\left(R^{2}=0.962\right)$. 
long four-century period and across a vastly changed world-has a systematic underlying structure, and is remarkably well captured by a Weibull distribution. The fact that this result is completely otiose does not diminish its uncanniness!

Why this underlying structure? In statistical theory, the Weibull function is an extreme value distribution, which captures the minimum value of a large collection of random observations. To clarify this point, consider for example a system with a large number $n$ of components placed in series to fulfill a specific function. The failure of any one component results in the failure of the system, its function is no longer provided. The time to failure of the system is therefore the minimum time to failure of any one of its component. Statistical extreme value theory tells us that regardless of the underlying failure distribution of the components, when $n$ is very large, the time to failure of the system approaches a Weibull distribution. Notice in this example the difference between component level and system level considerations, and how the result at the aggregate system level is independent of the failure distribution of any one component. Extreme value theory is also applicable in another related context: consider a single monolithic item. There are no components in this item. But assume that there are $n$ different competing failure processes of this item, whichever one occurs first breaks the item. When $n$ is very large, this will also result in a Weibull distribution of the time to failure of the item regardless of the distribution of each failure process.

The extension of these observations to the violent death of Roman emperors has to be done cautiously. But they offer nonetheless a fruitful venue for exploration. The fact that the time signature of the stochastic process of interest here is remarkably well captured by a Weibull distribution suggests that it is perhaps indeed the result of a very large number of underlying processes conspiring to violently eliminate the emperor. The fact that there were many pathways to the violent death of an emperor, with large numbers of individuals and motivations for undertaking the grisly task, makes the Weibull, an extreme value distribution, theoretically plausible in this case.

Mixture Weibull distributions. A closer inspection of Fig. 3 shows two distinctive slopes for the data points, before and after $\ln (t) \approx 2.5$, which corresponds to the onset of the wear-out failures seen in Fig. 2. A mixture Weibull distribution is therefore fitted to the data, and the maximum-likelihood estimates of its parameters are provided as follows:

$$
\widehat{S}(t)=0.876 \cdot \exp \left[-\left(\frac{t}{12.835}\right)^{0.618}\right]+0.124 \cdot \exp \left[-\left(\frac{t}{14.833}\right)^{13.387}\right]
$$

Equation (5) provides an analytical confirmation of the previous observations, that Roman emperors experienced both infant mortality $(\beta=0.618)$ and wear-out mortality $(\beta=13.387)$ in the form of violent death. This parametric result is shown in Fig. 4.

The emperors who experienced infant mortality were not unlike engineering components that suffer early failures after they are put to use: weak by design or fundamentally incapable of meeting the demands of their environment and circumstances. Examples from each century abound, for example Galba (d. 69 CE), Pertinax (d. 193 CE), Macrinus (d. 218 CE), and Severus II (d. $307 \mathrm{CE}$ ). These were times of upheaval, and in the first two cases, these turned out to be times of transition to new dynasties (the Flavian, and the Severan, respectively). Emperors' infant mortality can be seen, in part, as both causes and consequences of times of crisis and instability ${ }^{7}$.

The emperors who experienced wear-out mortality met their end through different failure mechanisms. Consider first that

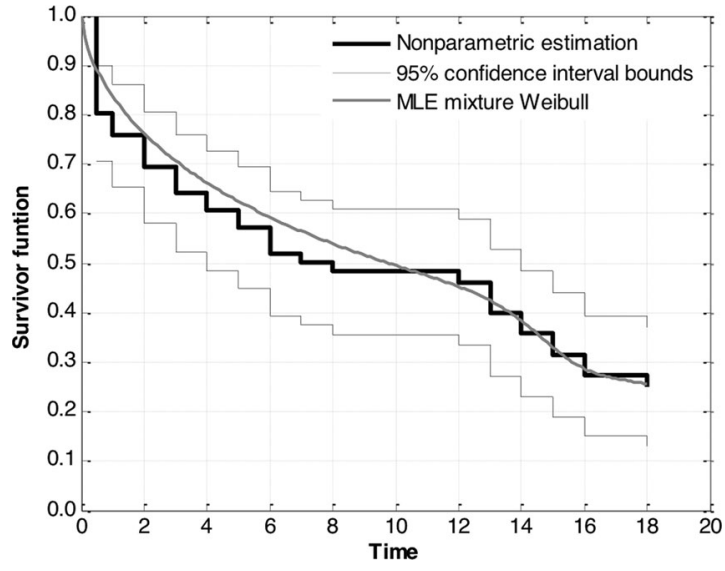

Fig. 4 Mixture Weibull survivor (reliability) function of Roman emperors, and the nonparametric results.

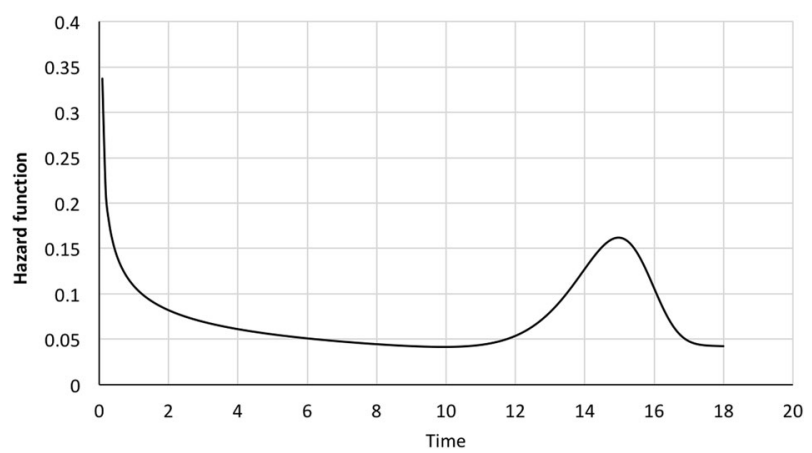

Fig. 5 Failure rate of Roman emperors (parametric fit of the time-to-violentdeath).

some engineering components experience an uptake in failures (wear-out failures) after they have been in service for a long time. They may have been sturdy at first and benefitted from clement operational environments to start with. But through degradation, fatigue, or increased harshness in their operational environment, they begin to experience wear-out failures. The emperors who survived the first 8 years of their rule, as seen in Fig. 2, had a grace period of about 4 years. Violent death came to them afterward (wear-out mortality) because, for instance, their old enemies had regrouped or new ones emerged, because they had alienated an increasing number of parties, or because new weaknesses in the imperial rule appeared or grew. These new murderous processes clearly had a different temporal signature than those driving the emperors' infant mortality, as seen in Fig. 3 and in the different characteristic life parameters of each Weibull distribution in Eq. (5). For example, the death of Domitian after a 15-year rule (d.96 $\mathrm{CE}$ ), or Commodus after a 12-year rule (d.192 CE), or Gallienus after a 15-year rule $(d .268 \mathrm{CE})$ are illustrative of wear-out mortality ${ }^{8}$.

The failure rate (Eq. (2)) of the parametric fit (Eq. (4)) is given in Fig. 5. The result shows a remarkable bathtub-like curve, a model widely used, and empirically confirmed in reliability engineering for a host of mechanical and electronic components. Roman emperors, like these engineering items, therefore experienced a bathtub-like failure rate.

The results in Fig. 5 lends themselves to an interesting interpretation:

i. The decreasing failure rate early on, the signature of infant mortality, reflects as noted previously a prevalence of weak 
emperors who were incapable at the onset of their rule to the handle the demands of their environment and circumstances. The fact that the failure rate was decreasing though suggests a competition between antagonistic processes, on the one hand those that sought to violently eliminate emperors (elimination), and on the other hand those that reflected the emperors learning curve to better protect themselves and perhaps eliminate their opponents (preservation). Examples abound in Roman history of this competition. Up to the first 12 years of one's rule, the preservation processes steadily improved their performance, and the situation can be casually summarized as "whatever didn't kill them [the Roman emperors] made them stronger" or less likely to meet a violent death;

ii. The increasing failure rate after 12 years of rule, the signature of wear-out failures, reflects as noted previously an uptake in failures through degradation with time, fatigue, or increased harshness in their circumstances. A growing mismatch between capabilities and demands under changing (geo-)political circumstances. This can be due to a number of reasons discussed previously. The fact that the failure rate was increasing after this 12-year mark suggests again a competition between the same antagonistic processes noted in (i), and this time the preservation ones were on the losing end of this competition. This result can be causally summarized as "whatever didn't kill them made them weaker" after a 12-year rule.

Beyond these specific details, what does it mean to find a coherent structure within a stochastic process of historical nature as the one here examined? Roughly speaking, the result implies the existence of systemic factors and some level of determinism, in an average sense or expected value, superimposed on the underlying randomness of the phenomenon here examined. In other words, the process is not completely aleatory; it has some deterministic factors overlaid on its randomness. Conan Doyle, in Sherlock Holmes: The Sign of Four, expressed this general idea rather accurately when he wrote:

While the individual man is an insoluble puzzle, in the aggregate he becomes a mathematical certainty. You can, for example, never foretell what any one man will do, but you can say with precision what an average number will be up to.

The results in this section suggest a similar idea underlies the violent death of Roman emperors.

Etiology and suggestion for future work. The previous subsections investigated the temporal signature of the phenomenon here examined, the violent death of emperors, a spectacle of brutality and violence not unlike the gladiatorial games, except it stretched over four centuries and affected the entire Roman world (Millar, 1977).

What has not been explored is the etiology or causal basis of this phenomenon, or why emperors repeatedly met violent deaths in the first place, not just temporally how. The immediate causes of violent deaths of Roman emperors are frequently discussed in the literature. They can be found for example in Scarre's (1995) "Chronicle of Roman Emperors", and a short summary is provided in Retief and Cilliers' (2005) "Causes of death among the Caesars (27 BC-AD 476)". The entries include statements such as "murdered by the sword/dagger [...]", "poisoned by [name of individual]", or "decapitated by the soldiers". These explanations are of little interest, and they do not reflect the complex nature of causality in this context. The causal basis of the phenomenon here examined intersects a number of fundamental issues in Roman history, the development and pathologies of the
Roman monarchy for example, the problem of imperial succession, the role of the praetorian guard, the loyalties of the legions, and the geographic extent and resources of the empire, to mention a few. These issues and the complex nature of their relations with the phenomenon here examined are left as a fruitful venue for Roman historians to examine. It is worth noting that the the spectacle of regicide of Roman emperors is related a reciprocal way, as both a causal factor and a consequence, to the decline and fall of the Roman empire. As such, it deserves careful attention in future work.

\section{Conclusion}

On his deathbed, Augustus called for a mirror, examined himself, and had his hair combed. Then, as Suetonius recounts ${ }^{9}$ :

he called in his friends and asked whether it seemed to them that he had played the comedy of life well. He added: since well I have played my part, all clap your hand, and from the stage dismiss me with applause.

Marcus Aurelius closed his Meditations on a similar, albeit more somber note, of life as a theater and actors sometimes getting dismissed from the stage after fewer than the whole five acts (Meditations, tr. 1989) "It does not matter", he adds stoically, "whether he beholds the world a longer or shorter time". This is a fitting metaphor for all Roman emperors, and it serves to frame the scope of this work, namely for how long the emperors "beheld the [Roman] world" before they were dismissed from the stage, violently if that was the case. Edward Gibbon offered a similar view for the entirety of the history of decline and fall of the Roman empire:

By a philosophic observer, the system of Roman government might have been mistaken for a splendid theater, filled with players of every character and degree, who repeated the language and imitated the passion of their original model.

This work began in jest by comparing Roman emperors with gladiators, and it noted that the odds of survival of the former were worse than those of the latter. There is perhaps more to this comparison than meets the eye. There was a particular appeal to gladiatorial games in the Roman world (Fagan, 2011). Whatever its reasons ${ }^{10}$, it is undeniable that these games offered a spectacle of extreme brutality, like an unscripted theatrical play with violence as the main protagonist, and gladiators the creative agents of its delivery. Roman emperors performed in similar games, except instead of delivering their role in single afternoon, they took several years, sometimes only a few months to complete it before they were dismissed from the stage. They also faced more diverse hazards, and stealthier adversaries than those encountered by the gladiators in the arena. Incidentally, the emperor Commodus would blur the line of this analogy and go down into the arena and fight gladiators (as well as wild beats).

In examining their time-to-violent-death, this work found that of Roman emperors experienced infant mortality as well as wearout failures. Their failure rate displayed a bathtub curve, similar to that of a host of mechanical engineering items and electronic components. More interestingly, it was found that a stochastic process as unconventional and haphazardous as the violent death of a Roman emperor has a definite underlying structure, and is remarkably well captured by a Weibull distribution. The interpretation and possible reasons for this result were discussed. Some fruitful venues for future work were proposed to help understand the deeper etiology of the violent deaths of Roman emperors.

In seeking to uncover the causal basis of the spectacle of imperial regicide, one important causal factor should not be overlooked. It was briefly hinted at earlier in the section "Data 
and methods", when Diocletian was being urged to reclaim the purple a few years after he had abdicated, he replied that he would never trade the peace and happiness of his garden "for the storms of a never-satisfied greed". Since Augustus and Marcus Aurelius conceived of life as a play, we leave it to a Greek playwright, Euripides, as quoted by Plutarch in the Life of Sulla, to present this final causal factor in the phenomenon here examined:

[...] passing afterwards through a long course of civil bloodshed and incurable divisions proved Euripides to have been truly wise and thoroughly acquainted with the causes of disorders in the body politic, when he forewarned all men to beware of Ambition, as of all the higher Powers [it is] the most destructive and pernicious to her votaries ${ }^{11}$.

A fundamental engine of the spectacle of regicide was not structural in nature, nor within the legions or the flawed system of government of the empire, but intrinsic to the actors themselves: they were votaries of Ambition on the stage of one of the most consequential adventure in human history that was the Roman empire. The individuals should not be neglected in future work. It was the mutual interactions between the motivations and ambitions of individuals on the one hand, Vespasian, Septimus Severus, and Diocletian for example, and the social, political, and military factors on the other hand that led to spectacle of regicide of Roman emperors. The whole was subject to historical contingencies and some level of randomness in the timing and alignment of factors. This observation harkens back to Caesar's "iacta alea est"; this work has shown that the die he cast, and every emperor after him, was loaded and not completely fair or aleatory.

\section{Data availability}

The dataset used in this work is publically available in De Imperatoribus Romanis, a peer-reviewed online encyclopedia of Roman emperors [DIR]: http://www.roman-emperors.org/.

Received: 20 June 2019; Accepted: 11 November 2019;

Published online: 23 December 2019

\section{Notes}

1 When calculated on a century basis, the statistics show the same order of magnitude. For example, in the first and fourth century CE, roughly $58 \%$ of the emperors suffered a violent death, and in the third century, $77 \%$, a reflection of the convulsion and crisis of the third century. Only during the second century does the rate fall to the low $30 \%$. This was the period of the "five good emperors", as Gibbon calls them, from Nerva ( $d$. 98) to Marcus Aurelius (d. 180).

2 The city of Orléans in France is named after him, and consequently, New Orleans. And by extension, with a bit of a stretch, one can associate with him Jazz!

3 This introduces a subtle bias in the analysis which has to be acknowledged. By focusing on legitimate emperors only, we discard the many contenders for the imperial power who failed to secure senate confirmation, and were thus killed usually early on after their uprising. Senate confirmation, however, sometimes came afterthe-fact as a recognition of a fait-accompli that a would-be usurper and or his legions made it to Rome and obtained the senatorial recognition of the emperorship. Suffice to remember that Vespasian for example, Septimius Severus, and Julian to mention a few were, for a brief time, usurpers before obtaining senate confirmation. The implications for our purposes is that this introduces a survivor bias in our analysis, and that the results in section "Results and discussion" for the survivor function are likely conservative and underestimate the spectacle of regicide of Roman emperors, especially in the first few years of their reign. We are grateful for an anonymous reviewer who brought this up to our attention.

4 Portrayed skillfully by Joaquim Phoenix in the movie Gladiator. Fans are still waiting for the second installment of this movie.

5 In a famous statement upon being urged to reclaim the purple, Diocletian is said to have replied, "if you could show the cabbage I planted with my own hands to your emperor, he definitely wouldn't dare suggest I replace the peace and happiness of this place with the storms of a never-satisfied greed" [Epitome de Caesaribus]. It is however not known what kind of cabbages he grew.
6 The data are assumed to be independent and identically distributed (iid), as generally done in survival data analysis. This assumption, however, may be challenged for some emperors (e.g., father-son pairs), and this constitutes a potential limitation of the analysis.

7 To paraphrase Thomas Paine, "these are times that try [an empire's] soul".

8 Each of these cases has an interesting underlying pathway to violent death. These narratives, however, are beyond the scope of this work.

9 It is enjoyable to imagine and hope that Suetonius' work be turned into a TV series someday. If this happens, what music would go with Augustus' death scene? Rex Tremendae from Mozart's requiem would be a good start as the camera pans outside his dwelling (he was on his way to Rome and had just passed Naples when his illness took him). He was one, a rex tremendae, and was on the verge of being deified. Then, within his dimly lit chamber, the music switches to the more intimate prelude of Bach's Cello Suite No. 2 in D minor. The music fades, labored breathing is heard, then, cue to the actor portraying Augustus...

10 One only needs to consider the current appeal of the mixed martial arts (MMA) bloody fights, and then add to that swords, spears, and tridents for example to understand the appeal of gladiatorial games.

11 A devoted follower or a zealous acolyte.

\section{References}

Amalberti R, Auroy Y, Berwick D, Barach P (2005) Five system barrier to achieving ultrasafe health care. Ann Intern Med 142(9):756-764

Coleridge ST (1983) Biographia literaria. In: Engell J, Bate WJ (eds.) The collected works of Samuel Taylor Coleridge. Princeton University Press, Princeton, USA

De Imperatoribus Romanis [DIR]. http://www.roman-emperors.org/. Accessed 10 May 2019, along with the article for each legitimate emperor therein.

Fagan GG (2011) From the lure of the arena: social psychology and the crowd at the Roman games. Cambridge University Press, Cambridge, UK

Høyland A, Rausand M (2009) System reliability theory. John Wiley \& Sons, Hoboken, USA

Marcus Aurelius (1989) "Meditations". Translation by A.S.L. Farquharson. Oxford University Press, Oxford, UK

Millar F (1977) Emperor in the Roman world. Duckworth Publishing, London, UK

Plutarch. The parallel lives. Loeb Classical Library, 1921. http://penelope.uchicago. edu/Thayer/e/roman/texts/plutarch/lives/home.html. Accessed 16 May 2019.

Retief FP, Cilliers L (2005) Causes of death among the Caesars (27 BC-AD 476). Acta Theol 26(2):89-106

Saleh JH, Marais K (2006) Highlights from the early (and pre-) history of reliability engineering. Reliabil Eng Syst Saf 91(2):249-256

Scarre C (1995) Chronicle of Roman emperors. Thames \& Hudson, London

Suetonius (1998) Lives of the twelve Caesars. Loeb Classical Library, Cambridge, USA

Watson A (1999) Aurelian and the third century. Routledge, New York, USA

\section{Competing interests}

The author declares no competing interests.

\section{Additional information}

Supplementary information is available for this paper at https://doi.org/10.1057/s41599019-0366-y.

Correspondence and requests for materials should be addressed to J.H.S.

Reprints and permission information is available at http://www.nature.com/reprints

Publisher's note Springer Nature remains neutral with regard to jurisdictional claims in published maps and institutional affiliations.

Open Access This article is licensed under a Creative Commons Attribution 4.0 International License, which permits use, sharing, adaptation, distribution and reproduction in any medium or format, as long as you give appropriate credit to the original author(s) and the source, provide a link to the Creative Commons license, and indicate if changes were made. The images or other third party material in this article are included in the article's Creative Commons license, unless indicated otherwise in a credit line to the material. If material is not included in the article's Creative Commons license and your intended use is not permitted by statutory regulation or exceeds the permitted use, you will need to obtain permission directly from the copyright holder. To view a copy of this license, visit http://creativecommons.org/ licenses/by/4.0/

(C) The Author(s) 2019 